\title{
Income Inequality and Economic Growth: Empirical Evidence from Bangladesh
}

\author{
Habiba Sultana ${ }^{1} \quad$ Md. Shafiqul Islam ${ }^{2} \quad$ Md. Ahasan Ul Haque ${ }^{3}$ Sonia Afrin Ale ${ }^{4 *}$ \\ 1.Department of Economics, Noakhali Science and Technology University, Bangladesh \\ 2.Assistant Professor, Department of Economics, Noakhali Science and Technology University, Bangladesh \\ 3.Lecturer, Department of Economics, Noakhali Science and Technology University, Bangladesh \\ 4.Assistant Professor, Department of Economics, Noakhali Science and Technology University, Bangladesh
}

\begin{abstract}
The main purpose of this work is to explore the relationship between income inequality and economic growth in Bangladesh. The study is based on time series data starting from 1973 to 2016 of Bangladesh. In this paper, we used the Augmented Dickey-Fuller (ADF) test for checking stationary of series. This study gives a hint that all the afore-mentioned series are stationary at first difference. This paper also incorporated the Johansen test for cointegration and Vector error correction model (VECM) to test the long run relationship between income inequality and economic growth rate. The results of the study indicate that economic growth and income inequality are cointegrated. This approach suggests that an inverse relationship exists between income inequality and economic growth rate. In other words, the higher economic growth rate results in lower income inequality and lower economic growth rate leads to higher income inequality. We find that income inequality plays a negative and significant role in economic growth.
\end{abstract}

Keywords: Income inequality, Economic growth, ADF, Cointegration test, VECM, Bangladesh.

DOI: $10.7176 / \mathrm{JESD} / 10-16-09$

Publication date: August $31^{\text {st }} 2019$

\section{Introduction}

High economic growth is an indicator of development in countries. In the absence of economic growth, the development process is considered failed to improve the welfare of the country. Therefore, the implementation of economic development activities is expected to be oriented to increase economic growth. Economic growth also serves as an essential indicator of welfare. However, high economic growth may not necessarily improve the distribution of income in the community. So, the relation between income distribution and economic growth has been a popular topic of recent economic research.

After the liberation period as a new country, the economic activity of Bangladesh grew at a slower rate but in the recent year's growth rate increases over time. Economic growth is considered to be a powerful force for reducing poverty. High and sustained economic growth increases the labor demand and wages which in return will reduce poverty. Better earnings as a result of the reduction in poverty lead to increase productivity and growth. But the extent of poverty reduction as a result of economic growth depends on how the distribution of income changes with economic growth and on initial Inequalities in income. The economic reform and the ensuing economic success has transformed Bangladesh from a relatively egalitarian society to a country with highly unequal distribution of income by world standards. Such observation has attracted increasing interest as well as debate in both academic and policy arenas concerning the extent to which the gains from our growth have been shared by different segments of its population and whether the rapidly rising inequality may eventually jeopardise its growth potential in the future.

The most used inequality measures are the Lorenz curve, the Gini coefficient and the dynamic test of inequality. The early debates on inequality-economic growth nexus were first introduced by Kuznets $(1955,1963)$, known as the Kuznets hypothesis. According to the hypothesis, economic growth and income inequality are coordinated in an inverted-U shaped curve. In other words, income distribution tends to worsen until countries achieve a threshold income level in the early phase of economic development. Then, in the later stage of the development process, inequality begins to decrease with the increase of per capita income.

Some studies provide different conclusions about the relationship between economic growth and income distribution. So, the relationship between the two variables is still challenging to understand and empirically still being controversial. Some of the empirical research that focuses on the Kuznets hypothesis has confirmed the causal relationship between economic growth and income inequality, while the others have questioned the results. Based on prior literature, the expected result is a negative relationship between income inequality and economic growth.

\section{Literature Review}

The effect of inequality on economic growth is a controversial issue. Existing pieces of literature find both positive and negative relationship. Following the remarkable work of Kuznets (1955), many studies have emerged, the 
relationship between growth and income inequality might be positive, but over time more income inequalities reduce economic growth, get inverted "U" shape of Kuznets curve. Assa (2012) finds a substantial adverse effect of income inequality on future growth using both OLS and 2SLS regressions an updated dataset of 141 countries in the period of 1998-2008. Grijalva(2011) conducts a study using restricted system-GMM estimators and gets evidence of a short-run inverse-u relationship between inequality and growth. Banerjee and Duflo (2003) using restricted system-GMM estimators show that the rate of economic growth is a quadratic function of net changes in the inequality measure. Pagano (2004) conducts a study with an extensive panel dataset of 138 countries, finds that there is a positive relationship in rich countries and negative relationship in the poor ones. Persson and Tabellini(1991) find a negative relationship using the income share of the top quintile of developed countries (1830-1985).Alesina and Rodrik (1994) address a negative relationship between income inequality and economic growth rate using 70 OCSE countries. Fawaz, Rahnama, and Valcarcel (2014) find strong evidence of a negative correlation between income inequality and economic growth in LIDC to be in stark contrast with a positive inequality-growth relationship for HIDC a total of 111 countries were sampled, using multiple linear regression models. Keefer and Knack (2000) address evidence of a negative correlation between income inequality and growth, but this correlation becomes insignificant once a measure of property rights is included as a control variable. Barro's(2000) study finds that inequality has a negative impact on growth in poor countries, but a positive effect on growth in rich countries. Panizza (2002) suggest the analysis of the relationship between inequality and growth within the United States, by using observations relative to the single states. The author, however, does not get statistically significant estimates for the coefficients corresponding to the inequality measures chosen. Clarke (1992) shows initial inequality is negatively correlated with growth and decreasing inequality from one standard deviation above to one standard deviation below is the mean increases in the long term growth rate by approximately $1.3 \%$ per annum in the context of the cross country. Forbes (2000) points out a positive relationship between inequality and growth using the series of sensitivity tests $t$ for a wide range of model specifications. Bias. $\mathrm{Li}$ and Zou (1998) obtain a positive estimated value of the coefficient relative to the inequality measure taken into account, the Gini coefficient considering the 1960-1990 period. The number of literature in the context of Bangladesh is inadequate. The debate between income inequality and GDP growth is neatly broadly opened for the further apocalypse. In this paper, we try to examine whether inequality hurts or benefits growth in Bangladesh from 1973 to 2016. Additionally, we use different variables than some of the literature as we attempt to improve on past models and include essential variables that have an impact on economic growth and income inequality

\section{Theoretical background}

The focus on income inequality and economic growth began in the 1950s when Simon Kuznets presented his idea to the American Economic Association of an inverted U relationship between per capita GNP and inequality in the distribution of income. Based upon income distribution data available at that time, Kuznets suggested that as per capita income rose in lesser developed countries, income inequality also rose, reached a maximum, and then declined as income levels rose to further. Kuznets developed this theory by studying data estimating income distribution in a few rich and a few poor countries and by analysing trends in distribution in a few European countries over time (Perkins et al., 129). His findings were an "inverted-U hypothesis."

\section{Data and methodology \\ 4.1 Data Source and Data Type}

The study is based on time series data starting from 1973 to 2016 of Bangladesh. All the data are sourced from World Development Indicator (WDI) of World Bank except income inequality. Income inequality data are collected from "The Standardized World Income Inequality" (SWIID) Version 5.0. There are total 44 observations for four variables. For the study on income inequality, I have used GDP growth rate (\%) as dependent variable. The focus independent variables here are income inequality (Gini -Coefficient), capital formation (\%) and government expenditure (billion taka).

\subsection{Econometric Characteristics of Data}

In the case of econometric analysis using time series data, the first and foremost criteria for the variables to have a long run relationship are that the variables should all be stationary. Otherwise, non-stationary variables can imply spurious relation among the variables. Therefore, we have to determine first whether the variables are stationary or not. If the variables are non-stationary, we have to make them stationary by using the differencing procedure. Now we examine stationarity of the four variables through unit root tests. For this analysis, we have conducted the Augmented Dickey-Fuller Test and Phillip-Perron Test to check whether the variables have a unit root or not. Using the logarithmic form of the two variables we define our model as the following in -log model. So the equation can be written as:-

$$
Y_{t}=\beta_{\circ}+\beta_{1} G I_{t}+\beta_{2} \ln C F_{t}+\beta_{3} \ln G E_{t}+\varepsilon_{t}
$$

Here, $\mathrm{Y}=$ the GDP growth rate, GI = Income Inequality (gini-coefficient), $\mathrm{CF}=$ capital formation, $\mathrm{GE}=$ 
government expenditure, $\beta_{0}=$ the constant term, $t$ denotes time, $\ln =$ the natural logarithm operator, and $\varepsilon_{t}=$ denotes residual.

\subsection{Unit Root Test}

\subsubsection{Augmented Dickey-Fuller Test (ADF)}

In case of augmented dickey fuller test, there may create a problem of autocorrelation. To tackle autocorrelation problem, dickey fuller have developed a test called Augmented Dickey Fuller test (ADF). The Augmented DickeyFuller test is a process to test unit root with the null hypothesis of the variables having unit root, which implies non stationarity of the variables. The alternative hypothesis implies stationarity as well. This is the most generalized test for stationarity. The test regression for ADF test is,

$\Delta \mathrm{Y}_{\mathrm{t}}=\alpha_{1}+\alpha_{2} t+\gamma \mathrm{Y}_{\mathrm{t}-1}+\alpha_{2} \mathrm{t}+\sum_{i=1}^{\rho} \beta_{\mathrm{i}} \Delta \mathrm{Y}_{\mathrm{t}-\mathrm{i}}+\varepsilon_{t}$

Here $\Delta$ is the first difference operator, and $\rho$ is the number of lags in the dependent variable. Where, null hypothesis is $\gamma=0$. rejecting null hypothesis means data is stationary and vice versa.

\subsection{Testing for Cointegration and Vector Error Correction}

Cointegration refers to the linear combination of some non-stationary variable that indicates a long-run equilibrium relationship among them. The primary criterion is all the variables should have the same cointegrating order. All our variables are I(1). We test for cointegration with all the I(1) variables in our model. For testing cointegration, we have used the Engle-Granger methodology and Johansen methodology.

\subsubsection{The Johansen Procedure}

The Johansen test allows for more than one integrating relationships. It relies on the relationship between the rank of a matrix and its characteristics root. The process can be shown,

$$
\Delta X_{t}=A_{0}+\pi X_{t-1}+\varepsilon_{t}
$$

It estimates the characteristic roots and eigen values as the following:

$$
\begin{gathered}
\lambda_{\text {trace }}(\mathrm{r})=-\mathrm{T} \sum_{i=r+1}^{n} \ln \left(1-\lambda^{\wedge}{ }_{i}\right) \\
\lambda_{\max }(\mathrm{r}, \mathrm{r}+1)=-\mathrm{T} \ln \left(1-\lambda^{\wedge}{ }_{r+1}\right)
\end{gathered}
$$

Here, $\lambda^{\wedge}$ is the estimated values of the characteristics roots or eigen values obtained from the estimated $\pi$ matrix.

\section{First test}

$\mathrm{H}_{0}$ : The number of distinct cointegrating vectors is less than or equal to $\mathrm{r}$.

Second test

$\mathrm{H}_{0}$ : The number of cointegrating vectors is $\mathrm{r}$ against the alternative of $\mathrm{r}+1$ cointegrating vectors.

Our analysis found evidence of existence of cointegrating vectors in Johansen test suggesting there is long relationship among the variables.

\subsubsection{Vector Error Correction model}

Vector error correction model shows the dynamic that how short-run converges to the long run minimizing fluctuations. Suppose the test regression is:-

$$
\begin{gathered}
\Delta Y_{t}=\delta_{\circ}+\sum_{j=1}^{\rho} \theta \Delta G I_{t-j}+\sum_{j=1}^{\rho} \omega_{k} \Delta \ln C F_{t-j}+\sum_{j=1}^{\rho} \varphi_{k} \Delta \ln G E_{t-j} \quad+\quad \lambda\left[Y_{t-1}-\right. \\
\left.G I_{t-1}-\widehat{\beta_{2}} \ln C F_{t-1}-\widehat{\beta_{3}} \ln G E_{t-1}\right]+\varepsilon_{t}
\end{gathered}
$$

The left hand side of the equation shows long run equilibrium with the coefficients reversing the sign for side changing. By this way we find cointegrating vector.

\section{Empirical Results and Discussion}

\subsection{Results of Augmented dickey fuller test}

According to Augmented Dickey Fuller Test (ADF), expect capital formation (CA), other three variables are nonstationary at level. After First order differentiation, (Table: 1) all non-stationary variables become stationary. Therefore all the variables integrated of order 1or I(1).

\section{Table 1: Results of Stationarity Tests (Augmented Dickey-Fuller)}

\begin{tabular}{|l|c|c|c|c|c|c|}
\hline & \multicolumn{3}{|c}{ Without trend } & \multicolumn{3}{c|}{ With trend } \\
\hline Variables & Level & $1^{\text {st }}$ Difference & Lag & Level & $1^{\text {st }}$ Difference & Lag \\
\hline Growthrate & -1.199 & $-6.951^{* * *}$ & 3 & $-6.219^{* * *}$ & $-9.631^{* * *}$ & 1 \\
\hline Giniindex & -0.584 & $-3.445^{* *}$ & 2 & -1.923 & $-3.227^{*}$ & 3 \\
\hline Lncaformation & $-8.620^{* * *}$ & $-16.270^{* * *}$ & 1 & $-8.456^{* * *}$ & $-15.982^{* * *}$ & 1 \\
\hline Lngovtexp & -1.619 & $-4.953^{* * *}$ & 1 & -2.971 & $-5.313^{* * *}$ & 1 \\
\hline
\end{tabular}

Notes: (i) figures within parentheses indicate lag lengths chosen by the Akaike Information Criterion (AIC); (ii) $*, * *$, and $* * *$ denote rejection of the null hypothesis of unit root at the $10 \%, 5 \%$, and $1 \%$ significance level respectively. 


\subsection{Result of Cointegration Test and Vector Error Correction Test Johansen tests for cointegration}

Our results suggest that there are co-integration among variables. Our first null hypothesis $\mathrm{r}=0$ means there is no cointegration and alternative hypothesis $\mathrm{r}=1$ implies at least one integrating equation. Our guideline is when trace or max statistics is higher than critical value then we can reject the null hypothesis $(\mathrm{r}=\mathrm{O})$. When null hypothesis $\mathrm{r}=0$, our trace statistics is greater than critical value then we reject the null hypothesis (There is no cointegrating relations, $\mathrm{r}=0$ ) and accept the alternative hypothesis (there is one cointegrating relation). When our null hypothesis $r \leq 1, r \leq 2, r \leq 3$ and alternative hypothesis are $r=2, r=3, r=4$ the values trace statistics are not greater than the critical value, so we accept the null hypothesis.

Table 2: Results of cointregation test (Johansen tests for cointegration)

\begin{tabular}{|c|c|c|c|c|}
\hline & \multicolumn{3}{|c|}{ Trace statistics } \\
\hline Null & $\mathrm{r}=0$ & $\mathrm{r} \leq 1$ & $\mathrm{r} \leq 2$ & $\mathrm{r} \leq 3$ \\
\hline Alternative & $\mathrm{r}=1$ & $\mathrm{r}=2$ & $\mathrm{r}=3$ & $\mathrm{r}=4$ \\
\hline Trace statistics & $105.5794^{* *}$ & 27.8272 & 11.2292 & 3.4985 \\
\hline $\begin{array}{c}\text { Critical value } \\
(5 \% \text { significant level })\end{array}$ & $(47.21)$ & $(29.68)$ & $(15.41)$ & $(3.76)$ \\
\hline Conclusion & \multicolumn{3}{|c|}{ One cointegrating vector } \\
\hline
\end{tabular}

Note: **, denote rejection of the null hypothesis of at Johansen tests for cointegration the $5 \%$ significance level.

The result for trace test shows, there is one cointegrating relations. The same result shows max statistics. When null hypothesis $r=0$, our max statistics is greater than critical value then we reject the null hypothesis (There is no cointegrating relations, $\mathrm{r}=0$ ) and accept the alternative hypothesis (there is one cointegrating relations). When our null hypothesis $r \leq 1, r \leq 2, r \leq 3$ and alternative hypothesis are $r=2, r=3, r=4$ the values trace statistics are not greater than the critical value, so we accept the null hypothesis.

Table 3: Results of Johansen Cointegration Test

\begin{tabular}{|c|c|c|c|c|}
\hline & \multicolumn{5}{|c|}{ Max statistics } \\
\hline Null & $\mathrm{r}=0$ & $\mathrm{r} \leq 1$ & $\mathrm{r} \leq 2$ & $\mathrm{r} \leq 3$ \\
\hline Alternative & $\mathrm{r}=1$ & $\mathrm{r}=2$ & $\mathrm{r}=3$ & $\mathrm{r}=4$ \\
\hline Statistics & $77.7522 * *$ & 16.5980 & 7.7307 & 3.4985 \\
\hline Critical value (5\% significant level) & 27.07 & 20.97 & 14.07 & 3.76 \\
\hline Conclusion & \multicolumn{4}{|c|}{ One cointegrating vector } \\
\hline
\end{tabular}

Note: $* *$, denote rejection of the null hypothesis of at Johansen tests for cointegration the $5 \%$ significance level.

According to trace and max statistics, two statistics provide the same decision. Best would be when both are giving the same decision that is more secure to decide whether we should run unrestricted VAR or VECM model. So we can easily run a vector error correction model. All variable must be non-stationary at a level, but when we convert them into the first difference, they must be stationary. Expect capital formation (CA); the other three variables are non-stationary at level. After First order differentiation, all non-stationary variables become stationary.

\subsection{Results of Vector Error Correction Model}

First, we test for a significant number of lags. Then we run the model Johansen tests for co-integration. From the Johansen tests for co-integration test, we obtained that there is one co-integrating vector. Our guideline is if at least one variable is cointegrated then we can easily run the VECM model.

Table 4: Result of Vector Error Correction Model

\begin{tabular}{|c|c|c|c|}
\hline Variables & Coefficient & $Z$ & $\mathrm{p}>|\mathrm{z}|$ \\
\hline Constant & 2.355548 & - & - \\
\hline GN & -.1959486 & -3.67 & 000 \\
\hline LnCF & 1.211245 & 9.09 & 000 \\
\hline LnGE & 1.263594 & 7.49 & 000 \\
\hline
\end{tabular}

According to VECM, we obtain that long-run relationship between income inequality and growth rate. From this table showed that all of the coefficient value is highly significant because Statistics value of all variable is greater than the critical value. By running this model we find a negative relationship between income inequality and growth rate in Bangladesh. And we also see that lnCF (capital formation) and lnGE (Government Expenditure) positive relationship associated with growth in Bangladesh.

From table 4 we can say that if income inequality increases by $1 \%$, the economic growth decreases on average by $.195 \%$ point. On the other hand, if capital formation increases and government expenditure increases $1 \%$ then GDP growth increases on average by $1.21 \%$ and $1.26 \%$ point. 


\section{Conclusion}

We notice that income inequality is a vital topic for debate last few decades. In this paper, we investigate the relationship between Economic growth and income inequality in Bangladesh during the period of 1973 to 2016. The empirical relationship between income inequality and economic growth has received much attention over the last decade. Many studies have found evidence of a negative correlation between these two variables. We see that capital formation and government expenditure plays a positive and significant role in economic growth. We also found that income inequality plays a negative role in economic growth. If income inequality decreases over time along with an increase in economic growth, then economic growth may lead to a significant reduction in poverty. If income inequality decreases over time, the economic growth rate of Bangladesh will be faster, and it will bring the country to prosperity.

\section{References}

Alesina, A., and D. Rodrik. (1994). Distributive Politics and Economic Growth. The Quarterly Journal of Economics, Vol. 109, No. 2, 465-490.

Assa, J. (2012). Inequality and growth re-examined. Technology and Investment, 3(01), 1.

Banerjee, A. V., \&Duflo, E. (2003). Inequality and growth: What can the data say?. Journal of economic growth, 8(3), 267-299.

Barro, R. J. (2000). Inequality and Growth in a Panel of Countries. Journal of economic growth, 5(1), 5-32.

Barro, R. J. (2003). Determinants of economic growth in a panel of countries. Annals of economics and finance, 4 , 231-274.

Barro, R. J. (1996). Determinants of economic growth: a cross-country empirical study (No. w5698). National Bureau of Economic Research.

Barro, R. J. (1999). Inequality, Growth and Investment.NBER Working Paper No. 7038.

Castelló-Climent, A. (2010). Inequality and growth in advanced economies: an empirical investigation. The Journal of Economic Inequality, 8(3), 293-321.

Easterly, W. (2007). Inequality does cause underdevelopment: Insights from a new instrument. Journal of Development Economics, 84(2), 755-776.

Forbes, K. J. (2000). A reassessment of the relationship between inequality and growth. American economic review, 90(4), 869-887.

Fawaz, F., Rahnama, M., \&Valcarcel, V. J. (2014). A refinement of the relationship between economic growth and income inequality. Applied Economics, 46(27), 3351-3361.

Grijalva, D. F. (2011). Inequality and Economic Growth: Bridging the Short-run and the Long-run.

Halter, D., Oechslin, M., \&Zweimüller, J. (2014). Inequality and growth: the neglected time dimension. Journal of economic Growth, 19(1), 81-104.

Kuznets, S. (1955). Economic growth and income inequality. The American economic review, 45(1), 1-28.

Knowles, S. (2005). Inequality and economic growth: the empirical relationship reconsidered in the light of comparable data. The Journal of Development Studies, 41(1), 135-159.

Keefer, P., \& Knack, S. (2002). Polarization, politics and property rights: Links between inequality and growth. Public choice, 111(1-2), 127-154.

Li, H., \&Zou, H. F. (1998). Income inequality is not harmful for growth: theory and evidence. Review of development economics, 2(3), 318-334.

Ostry, J. D., Berg, A., \&Tsangarides, C. G. (2014).Redistribution, inequality, and growth, IMF Staff Discussion Note SDN1402. International Monetary Fund, Washington.

Ostry, J., Berg, A., \&Tsangarides, C. (2014). Redistribution, Inequality, and Growth. IMF (International Monetary Fund) Staff Discussion Note. SDN/14/02. https://doi. org/10.5089/9781484352076.006.

Pagano, P. (2004). An empirical investigation of the relationship between inequality and growth, Vol. 536. Bancad'Italia.

Persson, T., \&Tabellini, G. (1991). Is inequality harmful for growth? Theory and evidence (No. w3599). National Bureau of Economic Research.

Partridge, M. D. (1997). Is inequality harmful for growth?. The American Economic Review, 87(5), 1019-1032.

Panizza, U. (2002). Income inequality and economic growth: evidence from American data. Journal of Economic Growth, 7(1), 25-41.

Perotti, R. (1992). Fiscal policy, income distribution, and growth. Columbia University. Department of Economics.

Perotti, R. (1996). Growth, income distribution, and democracy: What the data say. Journal of Economic growth, 1(2), 149-187.

Resarch, P., \& Clarke, G. R. (1992).More Evidence on Income Distribution and Growth.

Voitchovsky, S. (2005). Does the profile of income inequality matter for economic growth?. Journal of Economic growth, 10(3), 273-296. 
Voitchovsky, S. (2003). Does the profile of income inequality matter for economic growth? (No. 354).LIS Working Paper Series.

World Bank. July (2014). World Development Indicators.

Solt, Frederick. (2009). "Standardizing the World Income Inequality Database." Social Science Quarterly, 90(2):231-242.

Solt, Frederick. (2014). "The Standardized World Income Inequality Database.” Working paper. SWIID Version 5.0, October 2014 